\title{
Clinical and microscopic correlation of abnormal vaginal discharge
}

\author{
Usharani N., Swetha D.*
}

Department of Obstetrics and Gynecology, Vijayanagar Institute of Medical sciences, Ballari, Karnataka, India

Received: 02 February 2021

Revised: 11 February 2021

Accepted: 12 February 2021

\section{*Correspondence:}

Dr. Swetha D.,

E-mail: swethad8888@gmail.com

Copyright: (c) the author(s), publisher and licensee Medip Academy. This is an open-access article distributed under the terms of the Creative Commons Attribution Non-Commercial License, which permits unrestricted non-commercial use, distribution, and reproduction in any medium, provided the original work is properly cited.

\begin{abstract}
Background: Vaginal discharge in the reproductive age group is the most common complaint encountered everyday both by gynaecologists and general practitioners. The prevalence of vaginal discharge in India is estimated to be $30 \%$. Bacterial vaginosis is the most common cause, followed by Candidiasis and Trichomonasis. Aims and objectives of the study were to correlate clinical and microscopic methods for diagnosing abnormal vaginal discharge and to find out the most common cause of abnormal vaginal discharge in our set up.

Methods: The study was carried out in Gynaecological OPD of VIMS, Ballari. After thorough history and gynecological examination, three samples were collected from the posterior fornix of vagina using sterile cotton swabs. The first swab was used to detect trichomonas vaginalis using wet mount microscopy. The second swab was used to determine amine/fishy odour (Whiff test). The third swab was used for gram staining to diagnose Bacterial vaginosis and Candida. The Gram-stained slides was evaluated using Nugent's scoring system for detection of BV.

Results: Bacterial vaginosis constitutes the most common cause of vaginal discharge, followed by Candidiasis and then Trichomoniasis in our set up. The sensitivity of clinical diagnosis is $71.93 \%, 88.9 \%$, and $33.3 \%$ and specificity are $54.65 \%, 92.15 \%$ and $99.49 \%$ for Bacterial vaginosis, Candidiasis, and Trichomoniasis respectively.

Conclusions: The most ideal approach is the microbiological approach for the etiological diagnosis of symptomatic vaginal discharge. The most common cause of abnormal vaginal discharge is Bacterial vaginosis followed by Candidiasis and Trichomoniasis.
\end{abstract}

Keywords: Bacterial vaginosis, Candidiasis, Trichomoniasis, Vaginal discharge

\section{INTRODUCTION}

Vaginal discharge in the reproductive age group is the most common complaint. Encountered everyday both by gynaecologists and general practitioners. Symptomatic vaginal discharge is caused by inflammation due to infection of the vaginal mucosa. It occurs in $1-14 \%$ of all women in the reproductive age group and is responsible for 5-10 million OPD visits per year throughout the world. The prevalence of vaginal discharge in India is estimated to be $30 \% .^{1}$ Abnormal vaginal discharge is the second most common problem after menstrual disorders. ${ }^{2}$ One in ten women will present with vaginal discharge in the course of a year. ${ }^{3}$ Almost every fourth woman in gynaecological outpatient department has the complaint of vaginal discharge. ${ }^{4}$ Abnormal vaginal discharge also predisposes to significant morbidity in the form of pelvic inflammatory diseases, infertility, endometriosis, cuff cellulitis, urethral syndrome, pregnancy loss, preterm labour, to enumerate a few. Most common cause of symptomatic vaginal discharge is Bacterial vaginosis (33-47\%) followed by Candidiasis (20-40\%) and Trichomoniasis $(8-10 \%) .^{5-7}$ These three conditions account for $90 \%$ of all etiologies of abnormal vaginal discharge. Multiple infections can also coexist. ${ }^{6}$

Most of the time a presumptive diagnosis is made based on the nature of the discharge (clinical diagnosis), which 
is often inaccurate and incomplete. This eliminates the laboratory component (Microbiological diagnosis) leading to treatment mismanagement. ${ }^{8,9}$ To address the limitations of clinical diagnosis, the World Health Organisation (WHO) developed and advocated the Syndromic management approach. This approach is based on the identification of a relatively constant combination of symptoms and signs (syndrome) and on the knowledge of the most common causative organisms of these syndromes and their antimicrobial susceptibility. Antimicrobial regimens are chosen to cover the major pathogens responsible for the syndromes.

The main disadvantage of this management is the cost of over diagnosis and over treatment when multiple antimicrobials are given to patient where infection is caused by none or only one organism. Also to be considered are the risks of adverse drug reactions, alteration of normal vaginal flora and also the potential for developing antibiotic resistance in the community. ${ }^{8,9}$ The addition of a simple microscopic evaluation by Gram stain of the vaginal smear has evolved as a sensitive noncultural diagnostic technique for Bacterial vaginosis and Candidiasis. ${ }^{1,5}$ Direct microscopy (wet smear) of the vaginal discharge to visualize the motile Trichomonas vaginalis has been determined to be as accurate as culture for the diagnosis of Trichomoniasis. ${ }^{5}$ Objectives were to correlate clinical and microscopic methods for diagnosing abnormal vaginal discharge and to find out the most common cause of abnormal vaginal discharge in our set up.

\section{METHODS}

The study was conducted in patients attending Gynaecology OPD, Vijayanagar Institute of Medical Sciences, Ballari, for a period of one and half year (from November 2016 to April 2018). These were the patients who complained of abnormal vaginal discharge as their main or subsidiary symptom. It is a cross sectional study.

\section{Inclusion criteria}

Age group of 18-45 years, complaining of abnormal vaginal discharge were included in the study.

\section{Exclusion criteria}

Pregnancy, Puerperium, Post abortal women within 6 weeks, Women during menstrual bleeding, Women who have taken antibiotics or antifungals in past 1 week, Benign and malignant tumors of uterus and cervix, Women with laboratory confirmed STD, Women with IUCD/ proven foreign body, Women with predisposing factors like diabetes/ immunosuppression.

\section{Statistical analysis}

The data collected from the study variable was entered into a excel sheet. After appropriate data filtration, the data sheet was transferred to and analysed using SPSS Version 20.0 software. Descriptive statistics like percentages, mean and standard deviation were used to describe the study variables. Considering the microbiological diagnosis of vaginal discharge as gold standard, the utility of clinical diagnosis was assessed by calculating the sensitivity, specificity, PPV and NPV.

\section{Clinical observation}

The study included the examination of the vaginal status of all women in conjunction with gross characteristics of vaginal discharge. It was possible to classify the patients into four categories on the basis of vaginal discharge characteristics. The gross characteristics of the discharge were considered as of diagnostic value included volume, colour, odour, frothiness and consistency.

Tenderness of vaginal walls with inflammation of vulva and a green or yellow offensive irritating discharge associated with or without multiple small punctuate strawberry spots on the vaginal vault and portio vaginalis of the cervix and often with superficial erosion of the cervix was characteristic of Trichomonas infection. Cases revealing redness of vaginal wall with white patches or plaques of cheesy material adherent to the vagina, which when removed showed multiple petechial haemorrhagic areas. Also there was edema and soreness of the vulva associated with profuse irritating curdy type of vaginal discharge constituting monilial infections. Cases revealing thin, frothy, homogenous, irritating discharge which is malodorous but showed no gross pathological changes of the vagina and of vulva was suggestive of bacterial vaginosis. The remaining were assigned to undiagnosed category since the discharge presented mixed characteristics.

\section{Microbial examination}

Patient was placed in lithotomy position. Cusco's speculum was introduced per vaginally and then vaginal material was obtained from the posterior fornix with a sterile swab stick for Wet mount, Whiff test and Gram stain.

Gram stain slide is interpreted by using Nugent score. The diagnostic criteria used for microbiological diagnosis are: Bacterial vaginosis- A Gram stain score of seven or more based on the scoring system by Nugent et al. Candidiasis- If gram positive budding yeasts and pseudohyphae are seen on Gram stain or wet mount with $10 \% \mathrm{KOH}$. Trichomoniasis- If wet mount is positive for motile Trichomonas vaginalis. Haemoglobin estimation, peripheral blood smear examination, urine routine examination and microscopic examination carried out for each patient in OPD.

\section{Samples size of estimation}

200 patients presented with abnormal vaginal discharge. 


\section{RESULTS}

The present study was carried out to determine the correlation between the clinical and microscopic diagnosis of abnormal vaginal discharge. White discharge per vagina was the chief complaint in 200 cases attending Gynaec OPD.

The mean age of the study cases were 31.27 years. $50 \%$ were in the age group of 21-30 years followed by $38.5 \%$ between $31-40$ years, $8 \%$ between $41-45$ years, $3.5 \%$, $<20$ years, which is depicted in Table no-1.Majority of the subjects had completed their primary school $(60 \%)$ followed by high school (25\%), $10 \%$ illiterate, $3.5 \%$ completed 12th standard, $1.5 \%$ completed their degree. $94.5 \%$ of the subjects were housewives, $2.5 \%$ were farmers, $1.5 \%$ were teachers, $0.5 \%$ were staff nurse, $0.5 \%$ were tailor, $0.5 \%$ had business. $49 \%$ of the study population belong to lower middle class, followed by $27 \%$ middle class, $17 \%$ lower class, $7 \%$ upper middle. Majority $(33.5 \%)$ of the cases were para 2, followed by para 3 in $31 \%, 16.5 \%$ were para $1,9 \%$ para $4.5 \%$ patients were nulliparous and $5 \%$ are $>$ para 5 and maximum parity was 6 seen in 1 women as depicted in Table 1. Maximum cases $(42 \%)$ are seen between 16 months, followed by $31 \%$ seen within $<1$ month, $13.5 \%$ in 6-12 months, $7 \%$ in > 24months, $6.5 \%$ in $12-24$ months as depicted in Table 1. The most common associated symptom was itching seen in 50.5\% cases, followed by pain abdomen seen in $45.5 \%$ and burning micturition $45 \%$, dysuria in $15.5 \%$. Less common complaint was backache seen in $5 \%$ of cases, which is depicted in Table 2.

Table 1: Age, parity distribution and duration.

\begin{tabular}{|lllllllll|}
\hline \multicolumn{1}{|c}{ Age group } & Frequency & Percent & Parity & Frequency & Percent & Duration & Frequency & Percent \\
\hline$\leq$ 20 years & 7 & 3.5 & Para 0 & 10 & 5 & $\leq 1$ month & 62 & 31 \\
\hline 21-30 years & 100 & 50 & Para 1 & 33 & 16.5 & $1-6$ months & 84 & 42 \\
\hline 31-40 years & 77 & 38.5 & Para 2 & 67 & 33.5 & $6-12$ months & 27 & 13.5 \\
\hline$\geq$ 40 years & 16 & 8 & Para 3 & 62 & 31 & $12-24$ months & 13 & 6.5 \\
\hline & & & Para 4 & 18 & 9 & $>24$ months & 14 & 7 \\
\hline & & & Para $\geq 5$ & 10 & 5 & & & \\
\hline Total & 200 & 100 & Total & 200 & 100 & Total & 200 & 100 \\
\hline
\end{tabular}

Table 2: Associated symptoms.

\begin{tabular}{|lll|}
\hline Symptom & Frequency & Percent \\
\hline Burning micturition & 90 & 45 \\
\hline Pain abdomen & 91 & 45.5 \\
\hline Itching & 101 & 50.5 \\
\hline Dysuria & 31 & 15.5 \\
\hline Backache & 10 & 5 \\
\hline
\end{tabular}

Table 3: Comparison of clinical and microbiological diagnosis with respect to bacterial vaginosis.

\begin{tabular}{|llll|}
\hline $\begin{array}{l}\text { Clinical } \\
\text { diagnosis }\end{array}$ & $\begin{array}{l}\text { Microbiological } \\
\text { diagnosis }\end{array}$ & Total \\
\hline & Positive & Negative & \\
\hline Positive & $82(71.9)$ & $39(45.3)$ & $121(60.5)$ \\
\hline Negative & $32(28.1)$ & $47(54.7)$ & $79(39.5)$ \\
\hline Total & $114(100)$ & $86(100)$ & $200(100)$ \\
\hline
\end{tabular}

Out of 200 cases, clinically Bacterial vaginosis was found to be positive in 121 cases and microscopically in 114 cases. 82 cases were both clinically and microscopically positive for bacterial vaginosis. 39 cases were clinically positive but microscopically negative (39 cases were undiagnosed). 32 cases were clinically negative but microscopically positive (among 32 cases, Candidiasis were 9, Trichomonas were 2 and undiagnosed were 21). 47 cases out of 200 were both clinically and microscopically negative for bacterial vaginosis, which is depicted in Table 3. Of 200 cases, clinically Candidiasis was found to be positive in 23 cases and microscopically in 9 cases. 8 cases were both clinically and microscopically positive for Candidiasis (Among these 8, 5 were mixed infections-Bacterial vaginosis with Candidiasis) Fifteen cases were clinically positive but microscopically negative (Among these 15 cases, 6 cases were Bacterial vaginosis, 9 cases were undiagnosed). 1 case was clinically negative but microscopically positive (which was mixed infection, Bacterial vaginosis with Candidiasis, which was clinically Bacterial vaginosis). 176 out of 200 were both clinically and microscopically negative for Candidiasis, which is depicted in Table 4.

Table 4: Comparison of clinical and microbiological diagnosis with respect to candidiasis

\begin{tabular}{|llll|}
\hline $\begin{array}{l}\text { Clinical } \\
\text { diagnosis }\end{array}$ & \multicolumn{2}{l}{$\begin{array}{l}\text { Microbiological } \\
\text { diagnosis }\end{array}$} & Total \\
\hline & Positive & Negative & \\
\hline Positive & $8(88.9)$ & $15(7.9)$ & $23(11.5)$ \\
\hline Negative & $1(11.1)$ & $176(92.1)$ & $177(88.5)$ \\
\hline Total & $9(100)$ & $191(100)$ & $200(100)$ \\
\hline
\end{tabular}

Out of 200 cases, clinically Trichomoniasis was found to be positive in 2 cases and microscopically in 3 cases. 1 case was both clinically and microscopically positive for Trichomoniasis (which was mixed infection- Bacterial vaginosis with Trichomoniasis). 1 case was clinically 
positive but microscopically negative (Bacterial vaginosis microscopically). 2 cases were clinically negative but microscopically positive (Both were mixed infection with Bacterial vaginosis, 2 cases were undiagnosed clinically). 196 cases out of 200, were both clinically and microscopically negative for Trichomoniasis, which is depicted in Table 5.

Table 5: Comparison of clinical and microbiological diagnosis with respect to trichomoniasis

\begin{tabular}{|llll|}
\hline $\begin{array}{l}\text { Clinical } \\
\text { diagnosis }\end{array}$ & $\begin{array}{l}\text { Microbiological } \\
\text { diagnosis }\end{array}$ & Total \\
\hline & Positive & Negative \\
\hline Positive & $1(33.3)$ & $1(0.5)$ & $2(1.0)$ \\
\hline Negative & $2(66.7)$ & $196(99.5)$ & $198(99.0)$ \\
\hline Total & $3(100)$ & $197(100)$ & $200(100)$ \\
\hline
\end{tabular}

Out of 200 cases, clinically undiagnosed was found to be positive in 54 cases and microscopically in 82 cases. 34 cases were both clinically and microscopically undiagnosed. 20 cases were clinically positive but microscopically negative (among 20 negative, 19 were Bacterial vaginosis, one was mixed infection Bacterial vaginosis with Trichomoniasis). 48 cases were clinically negative but microscopically positive (Among these 48, 38 were Bacterial vaginosis, 10 were Candidiasis). 98 cases out of 200 were both clinically and microscopically negative, which is depicted in Table 6.

Table 6: Comparison of clinical and microbiological diagnosis with respect to undiagnosed cases.

\begin{tabular}{|c|c|c|c|}
\hline \multirow{2}{*}{$\begin{array}{l}\text { Clinical } \\
\text { diagnosis }\end{array}$} & \multicolumn{2}{|c|}{ Microbiological diagnosis } & Total \\
\hline & Positive & Negative & \\
\hline Positive & $34(41.5)$ & $20(16.9)$ & $54(27.0)$ \\
\hline Negative & $48(58.5)$ & $98(83.1)$ & $146(73.0)$ \\
\hline Total & $82(100)$ & $118(100)$ & $200(100)$ \\
\hline
\end{tabular}

Clinical diagnosis of Bacterial vaginosis, Candidiasis and Trichomoniasis have been validated with microbiological diagnosis as gold standard and found that clinical diagnosis had a sensitivity of $71.9 \%, 88.9 \%, 33.3 \%$ respectively and specificity of $54.7 \%, 92.2 \%, 99.5 \%$ respectively and PPV of $67.8 \%, 34.8 \%, 50.0 \%$ respectively and NPV of $59.5 \%, 99.4 \%, 98.99 \%$ respectively.

Table 7: Validation of clinical diagnosis with microbiological diagnosis as the gold standard.

\begin{tabular}{|lllll|}
\hline Clinical diagnosis & Bacterial vaginosis & Candidiasis & Trichomoniasis & Undiagnosed cases \\
\hline Sensitivity & $71.93 \%$ & $88.89 \%$ & $33.33 \%$ & $41.46 \%$ \\
\hline Specificity & $54.65 \%$ & $92.15 \%$ & $99.49 \%$ & $83.05 \%$ \\
\hline PPV & $67.77 \%$ & $34.78 \%$ & $50.00 \%$ & $62.96 \%$ \\
\hline NPV & $59.49 \%$ & $99.44 \%$ & $98.99 \%$ & $67.12 \%$ \\
\hline
\end{tabular}

\section{DISCUSSION}

Reproductive health has gained importance recently as reproductive tract infections, if not treated cause morbidity such as recurrent urinary tract infections, dyspareunia, menstrual irregularities, infertility, chronic pelvic pain, ectopic pregnancy, abortion, preterm labour, PROM, stillbirth, neonatal deaths, transmission of HIV infection and even maternal mortality. ${ }^{10}$

Gynecological infections, if not diagnosed and treated in time may lead to severe or irreversible complications. Due to changing microbiological profile of infection and sensitivity of microorganisms and emergence of $\beta$ lactamase and methicillin resistant pathogen and resistance to Azole group of drugs in non albicans is a major problem throughout the world in various clinical infections including Gynecological infections. Early microbiological diagnosis will help to plan accurate, appropriate and effective therapy. ${ }^{11}$

This prospective study included 200 women in whom criteria were assessed to compare the diagnosis of abnormal vaginal discharge by clinical and microbiological means. The most common associated symptom in the present study was vaginal itching $(50.5 \%)$ followed by pain abdomen $(45.5 \%)$ and burning micturition (45\%) comparable to studies done by Rao PS et al5, French et al. ${ }^{6}$ In present study patients sought medical help within 1-6months after the onset of symptoms, which was comparable to Rekha et al. ${ }^{12}$ Etiology was found in $126(63 \%)$ cases and was not found in $82(41 \%)$ by microbiological diagnosis. Microbiological diagnosis included 8 cases of mixed infection. In the present study Bacterial vaginosis (57\%) was the predominant cause of abnormal vaginal discharge followed by Vaginal candidiasis (4.5\%) and Trichomoniasis $(1.5 \%)$ which included mixed infections which is in correlation with the study of Rekha $S$ et al, Sowjanya et al and Vijayalakshmi et al. ${ }^{12-14}$

In our study, with respect to Bacterial vaginosis, clinically 82 cases $(71.9 \%)$ were correlating with microbiological diagnosis; with respect to Candidiasis, clinically 8 cases $(88.9 \%)$ were correlating with microbiological diagnosis and with respect to Trichomoniasis, clinically only 1 case $(33.3 \%)$ was correlating with microbiological diagnosis. Therefore Bacterial vaginosis and Trichomoniasis were more effectively diagnosed microscopically whereas clinically 
Candidiasis had a higher correlation with respect to microbiological diagnosis.

Hence, we conclude that Bacterial vaginosis has moderate sensitivity and low specificity, if we give empirical treatment as identified by clinical diagnosis some cases will receive treatment unnecessarily. Candidiasis has high sensitivity and specificity, emprical treatment as identified by clinical diagnosis is appropriate but microbiological diagnosis is ideal. Trichomoniasis has very high specificity and low sensitivity, so emprical treatment of cases as identified by clinical diagnosis some cases would be missed, therefore microbiological diagnosis is ideal even for Trichomoniasis.

WHO recommends that all women complaining of abnormal vaginal discharge be treated empirically with metronidazole and when Candida noted, to treat for Candidiasis as well. This study showed that $41 \%$ of patients had no TV, BV or Candidiasis by the microbiological diagnostic approach. If blanket treatment is advocated to all the women complaining of abnormal vaginal discharge then majority of the women would receive metronidazole and antifungal therapy unnecessarily. Not only does over diagnosis place a financial burden on the health system but it also carries the risk of possible social consequences in the community. Also, adverse effects of drugs may occur.

\section{Limitations}

Large population to be included to know the most common causes of abnormal vaginal discharge in the community, follow up of the patients was not done.

\section{CONCLUSION}

As abnormal vaginal discharge is one of the most common complaint in the reproductive age group, this study was undertaken to know the most common causes like Bacterial vaginosis, Candidiasis, Trichomoniasis both clinically and microscopically. Microbiological diagnosis is the ideal approach for etiological diagnosis of vaginal discharge. Nugent scoring is the gold standard test for diagnosis of Bacterial vaginosis. In a resource constrained setting, at least a clinical diagnosis based on simple microscopy, $\mathrm{pH}$ and amine test with WHO algorithms to be made prior to treatment.

\section{ACKNOWLEDGMENTS}

Authors would like to thank of VIMS Ballari, all the staff and all women who have participated in the study.

Funding: No funding sources

Conflict of interest: None declared

Ethical approval: The study was approved by the Institutional Ethics Committee

\section{REFERENCES}

1. Thulkar J, Kriplani A, Agarwal N, Vishnubhatla S. Aetiology\& risk factors of recurrent vaginitis \& its association with various contraceptive methods. Indian Journal of Medical Research. 2010 Jan $1 ; 131(1)$.

2. 2. Yudkin G. Vaginal discharge. In: Mc Pherson AA, editor. Women's Problems in General Practice. 2nd ed. Oxford: Oxford University Press; 1988.

3. 3. O'Dowd TC, West RR, Ribeiro CD, Smail JE, Munro JA. Contribution of Gardnerella vaginalis to vaginitis in a general practice. Br Med J (Clin Res Ed) 1986;292:1640-2.

4. 4. Koenig M, Jejeebhoy S, Singh S, Sridhar S. Investigating women's gynaecological morbidity in India: not just another KAP survey. Reprod Health Matters. 1998;6:1-13.

5. 5. Rao PS, Devi S, Shriyan A, Rajaram M, Jagdishchandra K. Diagnosis of Bacterial vaginosis in a rural setup: Comparison of clinical algorithm, smear scoring and culture by semiquantitative technique. Indian journal of medical microbiology. 2004 Jan 1;22(1):47.

6. 6. French L, Horton J, Matousek M. Abnormal vaginal discharge: what does and does not work in treating underlying causes. The Journal of family practice. 2004 Nov;53(11):890-4.

7. 7. Ryan CA, Zidouh A, Manhart LE, Selka R, Xia M, Moloney-Kitts M, Mahjour J, Krone M, Courtois BN, Dallabetta G, Holmes KK. Reproductive tract infections in primary healthcare, family planning, and dermatovenereology clinics: evaluation of syndromic management in Morocco. Sexually transmitted infections. 1998 Jun;74:S95-1

8. 8. Vishwanath S, Talwar V, Prasad R, Coyaji K, Elias CJ, de Zoysa I. Syndromic management of vaginal discharge among women in a reproductive health clinic in India. Sexually Transmitted Infections. 2000 Aug 1;76(4):303-6.

9. Malhotra M, Sharma JB, Batra S, Arora R, Sharma S. Ciprofloxacin-tinidazole combination, fluconazole-azithromicin-secnidazole-kit and doxycyclinemetronidazole combination therapy in syndromic management of pelvic inflammatory disease: a prospective randomized controlled trial. Indian J Med Sci. 2003;57(12):549-55.

10. Selvarani G. An Intervention programme for Reproductive tract infections among women in a selected area in rural Tamilnadu, India. South East Asain Studies Manual. 2000;2000:121-3.

11. Mehta VJ, Mehta SJ. Microbiological profile of abnormal vaginal discharge and its antimicrobial susceptibility pattern in a Tertiary Care Hospital, Gujarat. Indian Journal of Microbiology Research. 2017;4(3):303-15.

12. Rekha S, Jyothi S. Comparison of visual, clinical and microbiological diagnosis of symptomatic vaginal discharge in the reproductive age group. Int J Pharm Biomed Res. 2010;1(4):144-48. 
13. Sowjanya R, Prathyusha V, SaiSreeSudha R. Comparative study of visual, clinical and microbiological diagnosis of white discharge. J Dent Med Sci. 2015;14(11):24-7.

14. Vijayalakshmi D, Patil SS, Sambarey PW. Clinical and microscopic correlation of vaginal discharge. Int J Contemp Med Res. 2016;3(5):1328-31.
Cite this article as: Usharani N, Swetha D. Clinical and microscopic correlation of abnormal vaginal discharge. Int J Reprod Contracept Obstet Gynecol 2021;10:909-14. 